\title{
Intratumor heterogeneity of k-ras and p53 mutations among human colorectal adenomas containing early cancer
}

\author{
Walter Giaretti a,*, Barbara Macciocu ${ }^{\mathrm{a}}$, \\ Elio Geido ${ }^{a}$, Mario A.J.A. Hermsen ${ }^{b}$, \\ Cindy Postma ${ }^{\mathrm{b}}$, Jan P.A. Baak ${ }^{\mathrm{b}}$, \\ Richard A. Williams ${ }^{\mathrm{c}}$ and Gerrit A. Meijer ${ }^{\mathrm{b}}$ \\ ${ }^{a}$ Laboratory of Biophysics and Cytometry, National \\ Cancer Institute (IST), Genoa, Italy \\ ${ }^{\mathrm{b}}$ Department of Pathology, Free University Hospital, \\ Amsterdam, The Netherlands \\ c Department of Pathology, St. Vincent's Hospital, \\ Victoria, Australia
}

Received May 2000

Accepted 16 October 2000

The molecular pathways and the timing of genetic events during human colorectal carcinogenesis are still not fully understood. We have addressed the intratumor heterogeneity of the mutational status of the k-ras oncogene and of the p53 oncosuppressor gene during the adenoma-carcinoma sequence by investigating 26 human colorectal adenomas containing early cancer. An intratumor comparative analysis was obtained among the adenomatous and carcinomatous component pairs. Additionally, we have analyzed 17 adenomas having cancer in the near vicinity.

The adenomatous components of the adenomas containing early cancer and the adenomas having cancer in the near vicinity had comparable frequencies for $\mathrm{k}$-ras mutations ( 28 and $47 \%$ ) but different for $\mathrm{p} 53$ mutations ( 52 and $7 \%, p$-value $=0.01)$. Interestingly, the adenomatous and carcinomatous components of the adenomas containing early cancer were rarely heterogeneous for the k-ras mutational status (only in $13 \%$ of the cases) but were characterized by heterogeneity of the p53 status in $59 \%$ of the cases $(p$-value $<0.01)$. In addition, the mutations of p53 for the adenomatous components of the adenomas containing early cancer were statisti-

\footnotetext{
${ }^{*}$ Corresponding author: Dr. Walter Giaretti, Laboratory of Biophysics and Cytometry, National Cancer Institute (IST), Largo Rosanna Benzi 10, 16132 Genova, Italy. Tel.: +39010 5600969; Fax: +39010 5600711; E-mail: giaretti@hp380.ist.unige.it.
}

cally significantly associated with severe dysplasia ( $p$-value $=0.01$ ).

Intratumor homogeneity of k-ras status during the human colorectal adenoma-carcinoma sequence suggests that the role of k-ras is more related to tumor initiation than to tumor progression. On the contrary, intratumor heterogeneity of p53 mutations indicates that the type of the p53 mutations may also be relevant for selection and expansion of new subclones leading to tumor progression.

Keywords: Oncogenes, tumor suppressor genes, colorectal tumor progression, molecular biology

\section{Introduction}

The vast majority of human sporadic colorectal carcinomas are thought to derive from adenomas, through histologically well-defined steps characterized by increasing degrees of dysplasia. From the genetic point of view, colorectal cancer development and progression is considered to be due to the accumulation of several genetic events. Among these, inactivation of the APC oncosuppressor gene, mutations of the k-ras protoncogene, mutations and deletions of the p53 and DCC oncosuppressor genes, and still loss or inactivation of other oncosuppressor genes, as indicated by studies addressing loss of heterozygosity and cytogenetic alterations $[3,4,6,9,20,26,27,34,38]$.

The incidence of k-ras mutations in human colon aberrant crypt foci, which are considered to be early precursors of adenomas, has been reported to be up to $85 \%[31,32,37,40]$. In contrast, $\mathrm{k}$-ras mutations in sporadic adenomas and adenocarcinomas were reported to be only at $30-50 \%$ incidence, with a trend of higher incidence of mutations among the adenomas [9,38]. Thus, a k-ras mutation present in either aberrant crypt foci or in adenomas would not seem to provide a definitive growth advantage to colonic epithelial cells. This hypothesis for a role of k-ras in initiation more than in progression was further tested in the present 
study by comparing the adenomatous and carcinomatous components of human colorectal adenomas containing early cancer and adenomas having cancer in the near vicinity.

Ras proteins in structurally altered forms, due to the gene mutations, are thought to lead to mitogenic signals without ongoing stimulation by their normal upstream regulators, but their precise role in human colorectal cancer genesis and progression is still not fully understood $[3,19]$. Recently, new functions of the Ras proteins were suggested with the discovery of a plethora of new effector pathways and different cellular mechanisms. These include phosphorylation of transcription factors in the MAP kinase cascade [5] and association with proliferation $[1,2,36]$, apoptosis $[8,21$, 36], cytoskeleton organization [18,29], chromosome stability and aneuploidy [11-14,16,17,28].

The p53 oncosuppressor gene was found to be rarely mutated among human colorectal adenomas with mild or moderate dysplasia, though mutations were frequent in adenomas with severe dysplasia and adenocarcinomas [9]. The mutations of p53, disseminated along the five most conserved exons (exons 5a, 5b, 6,7 , and 8 ), were reported to interfere with its control functions. The p53 gene product represents an important cell cycle checkpoint associated to cell block in the G1 phase to drive cells either to DNA repair or apoptosis. These very important functions of p53 at the crossroads of proliferation, apoptosis and aneuploidy have been extensively investigated and are the subject of several excellent reviews [22,24,25]. Thus, when p53 mutations occur in human colorectal adenomas, it is likely that other genetic alterations may accumulate and lead to definitive malignant progression. Also, the degree of cell heterogeneity is expected to be high at these stages, due to selection and expansion of new subclones with novel genetic changes. New studies are needed to assess these hypotheses further. In the present study, we aimed to investigate the intratumor heterogeneity of k-ras and p53 mutations among the adenomatous and carcinomatous components of human sporadic colorectal adenomas containing early cancer. These relatively rare lesions should provide a unique model to contribute to a better understanding of the colorectal adenoma-carcinoma transition.

\section{Materials and methods}

\subsection{Study population and histological analysis}

The study was carried out on 11 females and 16 males, in the age-range $45-86$ (median age 66.5 years), who did not have a history of familial adenomatous polyposis. We have considered two categories of colorectal adenomas, i.e., 26 adenomas containing early cancer $(\mathrm{A} / \mathrm{C})$ and 17 adenomas having cancer in the near vicinity $(\mathrm{A}+\mathrm{C})$. Table 1 reports the list of the cases with site, size, type, and dysplasia. The site was in the right bowel (including caecum, ascending colon, hepatic flexure and transverse colon) for 21 adenomas and in the left bowel (including splenic flexure, descending colon, sigmoid colon and rectum) for 22 cases. The size of the adenomas ranged from 3.5 to $80 \mathrm{~mm}$ (11 were smaller than $10 \mathrm{~mm}, 16$ were $10-20 \mathrm{~mm}$, and 16 were greater than $20 \mathrm{~mm}$ ). Considering the adenomatous components of the adenomas containing early cancer, the histological type was tubular for 17 cases and tubulovillous or villous for 25 . In one case this information was missing. Dysplasia was graded according to Konishi and Morson [23] and mild and moderate dysplasia cases were taken together as one group $(n=28)$ versus severe dysplasia $(n=15)$.

Using a hematoxylin-eosin stained section as histotopographic reference, samples were taken by hand with a scalpel blade from selected prevalent areas with homogeneous grades of dysplasia. Areas with prevalent connective tissue, inflammatory cells, and normal epithelial cells were discarded as much as possible.

\section{2. $k$-ras mutation spectrum analysis}

Extracted DNA from peripheral blood lymphocytes from healthy donors was used as wild type k-ras codon 12 GGT-gly and codon 13 GGC-gly controls. Additionally, extracted DNA from 6 different colon cancer cell lines was used as control for known k-ras mutations as previously described [15]. Extraction of high molecular weight genomic DNA was performed according to standard methods [35] and amplified by PCR as previously described [14]. Oligonucleotide 20mers panel (TIB MOLBIOL, Advanced Biotechnology Center, Genoa, Italy) including k-ras codon 12 and 13 wild type sequences, all possible mutations of codon 12 , and the AGC and GAC mutations of codon 13 were $5^{\prime}$-end labeled by phosphorylation with $\left[\gamma^{32} \mathrm{P}\right] \mathrm{ATP}$ (Amersham International, Buckinghamshire, UK), according to the standard method [35]. Dot blot and sequence specific oligonucleotide hybridization was performed as usual [14]. 
Table 1

Site, size, type, and dysplasia of 26 adenomas containing early cancer $(\mathrm{A} / \mathrm{C})$ and 17 adenomas having cancer in the near vicinity $(\mathrm{A}+\mathrm{C})$

\begin{tabular}{|c|c|c|c|c|c|}
\hline N. & Category & Site & Size $(\mathrm{mm})$ & Type & Dysplasia \\
\hline 1 & $\mathrm{~A} / \mathrm{C}$ & $\mathrm{L}$ & 11 & $\mathrm{~T}$ & $\mathrm{~S}$ \\
\hline 2 & $\mathrm{~A} / \mathrm{C}$ & $\mathrm{L}$ & 30 & $\mathrm{TV}$ & $\mathrm{S}$ \\
\hline 3 & $\mathrm{~A} / \mathrm{C}$ & $\mathrm{L}$ & 32 & $\mathrm{~T}$ & MM \\
\hline 4 & $\mathrm{~A} / \mathrm{C}$ & $\mathrm{L}$ & 29 & TV & $S$ \\
\hline 5 & $\mathrm{~A} / \mathrm{C}$ & $\mathrm{L}$ & 20 & $\mathrm{TV}$ & $\mathrm{MM}$ \\
\hline 6 & $\mathrm{~A} / \mathrm{C}$ & $\mathrm{R}$ & 75 & $\mathrm{~V}$ & MM \\
\hline 7 & $\mathrm{~A} / \mathrm{C}$ & $\mathrm{R}$ & 26 & TV & MM \\
\hline 8 & $\mathrm{~A} / \mathrm{C}$ & $\mathrm{R}$ & 60 & TV & MM \\
\hline 9 & $\mathrm{~A} / \mathrm{C}$ & $\mathrm{L}$ & 20 & TV & $\mathrm{S}$ \\
\hline 10 & $\mathrm{~A} / \mathrm{C}$ & $\mathrm{R}$ & 80 & TV & $\mathrm{S}$ \\
\hline 11 & $\mathrm{~A} / \mathrm{C}$ & $\mathrm{L}$ & 20 & TV & MM \\
\hline 12 & $\mathrm{~A} / \mathrm{C}$ & $\mathrm{R}$ & 18 & $\mathrm{~T}$ & $\mathrm{~S}$ \\
\hline 13 & $\mathrm{~A} / \mathrm{C}$ & $\mathrm{R}$ & 15 & $\mathrm{TV}$ & MM \\
\hline 14 & $\mathrm{~A} / \mathrm{C}$ & $\mathrm{R}$ & 40 & TV & $\mathrm{S}$ \\
\hline 15 & $\mathrm{~A} / \mathrm{C}$ & $\mathrm{R}$ & 10 & $\mathrm{~T}$ & $\mathrm{~S}$ \\
\hline 16 & $\mathrm{~A} / \mathrm{C}$ & $\mathrm{L}$ & 15 & $\mathrm{~T}$ & $\mathrm{~S}$ \\
\hline 17 & $\mathrm{~A} / \mathrm{C}$ & $\mathrm{R}$ & 50 & $\mathrm{TV}$ & MM \\
\hline 18 & $\mathrm{~A} / \mathrm{C}$ & $\mathrm{R}$ & 10 & $\mathrm{~T}$ & $\mathrm{~S}$ \\
\hline 19 & $\mathrm{~A} / \mathrm{C}$ & $\mathrm{L}$ & 10 & TV & $S$ \\
\hline 20 & $\mathrm{~A} / \mathrm{C}$ & $\mathrm{L}$ & 80 & - & MM \\
\hline 21 & $\mathrm{~A} / \mathrm{C}$ & $\mathrm{R}$ & 20 & TV & MM \\
\hline 22 & $\mathrm{~A} / \mathrm{C}$ & $\mathrm{R}$ & 35 & TV & S \\
\hline 23 & $\mathrm{~A} / \mathrm{C}$ & $\mathrm{L}$ & 20 & $\mathrm{TV}$ & $\mathrm{S}$ \\
\hline 24 & $\mathrm{~A} / \mathrm{C}$ & $\mathrm{L}$ & 55 & $\mathrm{TV}$ & MM \\
\hline 25 & $\mathrm{~A} / \mathrm{C}$ & $\mathrm{L}$ & 3.5 & $\mathrm{~T}$ & MM \\
\hline 26 & $\mathrm{~A} / \mathrm{C}$ & $\mathrm{L}$ & 75 & $\mathrm{~V}$ & MM \\
\hline 1 & $\mathrm{~A}+\mathrm{C}$ & $\mathrm{L}$ & 5 & TV & MM \\
\hline 2 & $\mathrm{~A}+\mathrm{C}$ & $\mathrm{L}$ & 15 & $\mathrm{~T}$ & MM \\
\hline 3 & $\mathrm{~A}+\mathrm{C}$ & $\mathrm{R}$ & 5 & $\mathrm{~T}$ & MM \\
\hline 4 & $\mathrm{~A}+\mathrm{C}$ & $\mathrm{R}$ & 29 & TV & MM \\
\hline 5 & $\mathrm{~A}+\mathrm{C}$ & $\mathrm{R}$ & 30 & TV & MM \\
\hline 6 & $\mathrm{~A}+\mathrm{C}$ & $\mathrm{R}$ & 24 & TV & $\mathrm{S}$ \\
\hline 7 & $A+C$ & $\mathrm{~L}$ & 10 & $\mathrm{~T}$ & MM \\
\hline 8 & $\mathrm{~A}+\mathrm{C}$ & $\mathrm{L}$ & 9 & TV & MM \\
\hline 9 & $\mathrm{~A}+\mathrm{C}$ & $\mathrm{L}$ & 11 & $\mathrm{~T}$ & MM \\
\hline 10 & $\mathrm{~A}+\mathrm{C}$ & $\mathrm{L}$ & 11 & $\mathrm{~T}$ & MM \\
\hline 11 & $\mathrm{~A}+\mathrm{C}$ & $\mathrm{R}$ & 10 & $\mathrm{~V}$ & MM \\
\hline 12 & $\mathrm{~A}+\mathrm{C}$ & $\mathrm{R}$ & 15 & $\mathrm{~T}$ & $\mathrm{~S}$ \\
\hline 13 & $\mathrm{~A}+\mathrm{C}$ & $\mathrm{R}$ & 16 & TV & MM \\
\hline 14 & $\mathrm{~A}+\mathrm{C}$ & $\mathrm{L}$ & 20 & $\mathrm{~T}$ & MM \\
\hline 15 & $\mathrm{~A}+\mathrm{C}$ & $\mathrm{L}$ & 18 & $\mathrm{~T}$ & MM \\
\hline 16 & $A+C$ & $\mathrm{R}$ & 9 & $\mathrm{~T}$ & MM \\
\hline 17 & $\mathrm{~A}+\mathrm{C}$ & $\mathrm{R}$ & 8 & $\mathrm{~T}$ & MM \\
\hline
\end{tabular}

Right colon ( $\mathrm{R}$ ) includes caecum, ascending colon, hepatic flexure, and transverse colon; Left colon (L) includes splenic flexure, descending and sigmoid colon, and rectum. $\mathrm{T}=$ tubular type; $\mathrm{TV}=$ tubulovillous type; $\mathrm{V}=$ villous type. $\mathrm{MM}=$ mild and moderate.

\section{3. p53 mutation analysis}

Starting from about $400 \mathrm{ng}$ of extracted DNA (see above), the genomic region encompassing exons 5-8 was first amplified with GC-clamped ampliprimers as previously described [7]. The PCR products obtained were analyzed by Denaturating Gradient Gel Electrophoresis (DGGE) as previously detailed [7]. After electrophoresis, the gels were stained for $20 \mathrm{~min}$ in $0.5 \mu \mathrm{g} / \mathrm{ml}$ ethidium bromide, visualized using an ultraviolet transilluminator and photographed using Polaroid type 57 films.

\subsection{Statistical analysis}

Contingency tables (Chi-square and Fisher exact test) were used to evaluate the associations among $\mathrm{k}$ ras and p53 status with site, size, type and dysplasia of the adenomas. Statistical significance was set at $p$ value $=0.05[10]$.

\section{Results}

The material for the study was composed of $26 \mathrm{hu}-$ man colorectal adenomas containing early cancer and 17 adenomas having cancer in the near vicinity. Table 1 reports the list of the cases together with site of origin, size, type, and degree of dysplasia.

The adenomatous components of the adenomas containing early cancer showed a statistically significantly higher frequency of severe dysplasia than the adenomas with cancer in the near vicinity $(50 \%$ versus $12 \%$; $p$-value $=0.02$; Table 2 ). The adenomatous components of the adenomas with early cancer also showed a slightly higher proportion of cases with a villous pattern $(69 \%$ versus $41 \%$; $p$-value $=0.06)$ and were more often with size greater than $20 \mathrm{~mm}$ (50\% versus 17\%; $p$-value $=0.06)$ than the adenomas with cancer in the near vicinity, but the differences were not statistically significant. The sites of origin of the adenomas containing early cancer and the adenomas having cancer in the near vicinity were, instead, comparable.

Analyses of k-ras and p53 mutations for both categories of adenomas were performed after PCR amplification of the extracted genomic DNA at exon 1 codons 12-13 for k-ras and for exons 5-8 for p53, respectively. Figures 1 and 2 show examples of the k-ras and p53 mutations obtained, respectively, by sequence specific oligonucleotide hybridization and DGGE. The cases with k-ras mutations are for the 6 possible mutations 
Table 2

Comparison of site, size, type, and dysplasia grade for 26 colorectal adenomas containing early cancer (A/C) and 17 adenomas having cancer in the near vicinity $(\mathrm{A}+\mathrm{C})$. Type and dysplasia of $\mathrm{A} / \mathrm{C}$ lesions refer to their adenomatous components $(\mathrm{A})$

\begin{tabular}{|c|c|c|c|c|c|c|c|c|c|}
\hline & \multicolumn{2}{|c|}{ Site } & \multicolumn{3}{|c|}{ Size $(\mathrm{mm})$} & \multicolumn{2}{|c|}{ Type } & \multicolumn{2}{|c|}{ Dysplasia } \\
\hline & $\mathrm{R}$ & $\mathrm{L}$ & $\leqslant 10$ & $>10$ and $\leqslant 20$ & $>20$ & $\mathrm{~T}$ & $\mathrm{TV}+\mathrm{V}$ & MM & S \\
\hline $\mathrm{A} / \mathrm{C}$ & 12 & $14(54 \%)$ & 4 & 9 & $13(50 \%)$ & 7 & $18(69 \%)$ & 13 & $13(50 \%)$ \\
\hline $\mathrm{A}+\mathrm{C}$ & 9 & $8(47 \%)$ & 7 & 7 & $3(17 \%)$ & 10 & $7(41 \%)$ & 15 & $2(12 \%)$ \\
\hline$p$-values & \multicolumn{2}{|c|}{$p=0.76$} & \multicolumn{3}{|c|}{$p=0.06$} & \multicolumn{2}{|c|}{$p=0.06$} & \multicolumn{2}{|c|}{$p=0.02$} \\
\hline
\end{tabular}
sigmoid colon and rectum. $\mathrm{T}=$ tubular type; $\mathrm{TV}=$ tubulovillous type; $\mathrm{V}=$ villous type. $\mathrm{MM}=$ mild and moderate dysplasia; $\mathrm{S}=$ severe dysplasia.

in codon 12 (AGT-ser, TGT-cys, CGT-arg, GAT-asp, GCT-ala, GTT-val) and the 2 most common mutations in codon 13 (AGC-ser, GAC-asp) as shown in Fig. 1 (from 2nd top left rectangle to 9th bottom right rectangle). Identical k-ras mutations for the adenomatous and carcinomatous components of 4 adenomas containing early cancer (these cases are listed in Tables 1 and 3 under the cases N. 4, 14, 21 and 26) corresponding to the pairs of spots GAT (b5-b6), GTT (c1-c2), GTT (d5-d6), and GAC (a5-a6) may be observed (see also the legend to the figure for more details).

Mutations of p53 within exons 5 to 8 were detected by comparison of the electrophoresis migration patterns with respect to the genomic DNA extracted from negative and positive controls. The presence of a fourband pattern in the case of heterozygous mutation is due to the simultaneous presence of wild type and mutated alleles (as in the examples of Fig. 2 for lanes $\mathrm{A}, \mathrm{H}$, and I of exon 8) that generate two heteroduplex combinations (wild type/mutated) and two homoduplex combinations (wild type/wild type and mutated/mutated; see also the legend to the figure for more details).

Table 3 shows the k-ras and p53 mutation data obtained for the adenomatous and carcinomatous components of the adenomas containing early cancer. The adenomatous components had frequencies for $\mathrm{k}$-ras and p53 mutations of $28 \%$ (7/25) and 52\% (12/23), respectively. The corresponding frequencies for the carcinomatous components were $28 \%$ (7/25) for k-ras and $64 \%(16 / 25)$ for $\mathrm{p} 53$. One may also notice that 2 different mutations were present for $\mathrm{k}$-ras in the carcinomatous component of adenoma N. 20 and for p53 in the carcinomatous components of adenomas N. 10 and 13.

Component pairs were obtained in 24 out of 26 cases for $\mathrm{k}$-ras and in 22 cases for p53. While the adenomatous and carcinomatous components rarely presented differences for k-ras, heterogeneity of the p53 status was commonly detected. Overall, intratumor k-ras het-
Table 3

Analysis of k-ras and p53 mutations for 26 human colorectal adenomas containing early cancer (A/C). Adenomatous (A) and carcinomatous $(\mathrm{C})$ components were analysed separately

\begin{tabular}{|c|c|c|c|c|c|}
\hline \multirow[t]{2}{*}{$\mathrm{N}$. } & \multirow[t]{2}{*}{ Category } & \multicolumn{2}{|c|}{ k-ras } & \multicolumn{2}{|c|}{ p53 } \\
\hline & & A & $\mathrm{C}$ & A & $\mathrm{C}$ \\
\hline 1 & $\mathrm{~A} / \mathrm{C}$ & wt & wt & Ex.5B & Ex.7 \\
\hline 2 & $\mathrm{~A} / \mathrm{C}$ & wt & wt & Ex.6 & Ex.6 \\
\hline 3 & $\mathrm{~A} / \mathrm{C}$ & wt & wt & wt & wt \\
\hline 4 & $\mathrm{~A} / \mathrm{C}$ & GAT & GAT & Ex. 8 & wt \\
\hline 5 & $\mathrm{~A} / \mathrm{C}$ & GAT & GAT & - & Ex.6 \\
\hline 6 & $\mathrm{~A} / \mathrm{C}$ & wt & - & wt & - \\
\hline 7 & $\mathrm{~A} / \mathrm{C}$ & TGT & wt & wt & wt \\
\hline 8 & $\mathrm{~A} / \mathrm{C}$ & wt & wt & Ex.6 & Ex.7 \\
\hline 9 & $\mathrm{~A} / \mathrm{C}$ & wt & wt & Ex.7 & Ex.8 \\
\hline 10 & $\mathrm{~A} / \mathrm{C}$ & wt & wt & Ex.6 & Ex.5B Ex.6 \\
\hline 11 & $\mathrm{~A} / \mathrm{C}$ & wt & wt & wt & wt \\
\hline 12 & $\mathrm{~A} / \mathrm{C}$ & wt & wt & Ex.8 & Ex.7 \\
\hline 13 & $\mathrm{~A} / \mathrm{C}$ & wt & wt & wt & Ex.6 Ex.8 \\
\hline 14 & $\mathrm{~A} / \mathrm{C}$ & GTT & GTT & wt & Ex.8 \\
\hline 15 & $\mathrm{~A} / \mathrm{C}$ & wt & wt & Ex.5B & Ex.5B \\
\hline 16 & $\mathrm{~A} / \mathrm{C}$ & wt & wt & wt & Ex.6 \\
\hline 17 & $\mathrm{~A} / \mathrm{C}$ & wt & AGT & - & wt \\
\hline 18 & $\mathrm{~A} / \mathrm{C}$ & wt & wt & wt & wt \\
\hline 19 & $\mathrm{~A} / \mathrm{C}$ & wt & wt & Ex.5B & wt \\
\hline 20 & $\mathrm{~A} / \mathrm{C}$ & - & GAT+GAC & - & Ex.6 \\
\hline 21 & $\mathrm{~A} / \mathrm{C}$ & GTT & GTT & wt & Ex.6 \\
\hline 22 & $\mathrm{~A} / \mathrm{C}$ & wt & wt & Ex. 8 & Ex.8 \\
\hline 23 & $\mathrm{~A} / \mathrm{C}$ & wt & wt & Ex.6 & Ex.6 \\
\hline 24 & $\mathrm{~A} / \mathrm{C}$ & GAT & wt & wt & wt \\
\hline 25 & $\mathrm{~A} / \mathrm{C}$ & wt & wt & wt & Ex.8 \\
\hline 26 & $\mathrm{~A} / \mathrm{C}$ & GAC & GAC & Ex.7 & wt \\
\hline
\end{tabular}

Sufficient material was not available for the analysis of the cases in which a dotted line was drawn.

erogeneity between the adenomatous and carcinomatous components was present only in the pair cases N. 7, 17 and 24. Table 4 reports in detail the heterogeneous cases for both k-ras and p53 genetic status. 

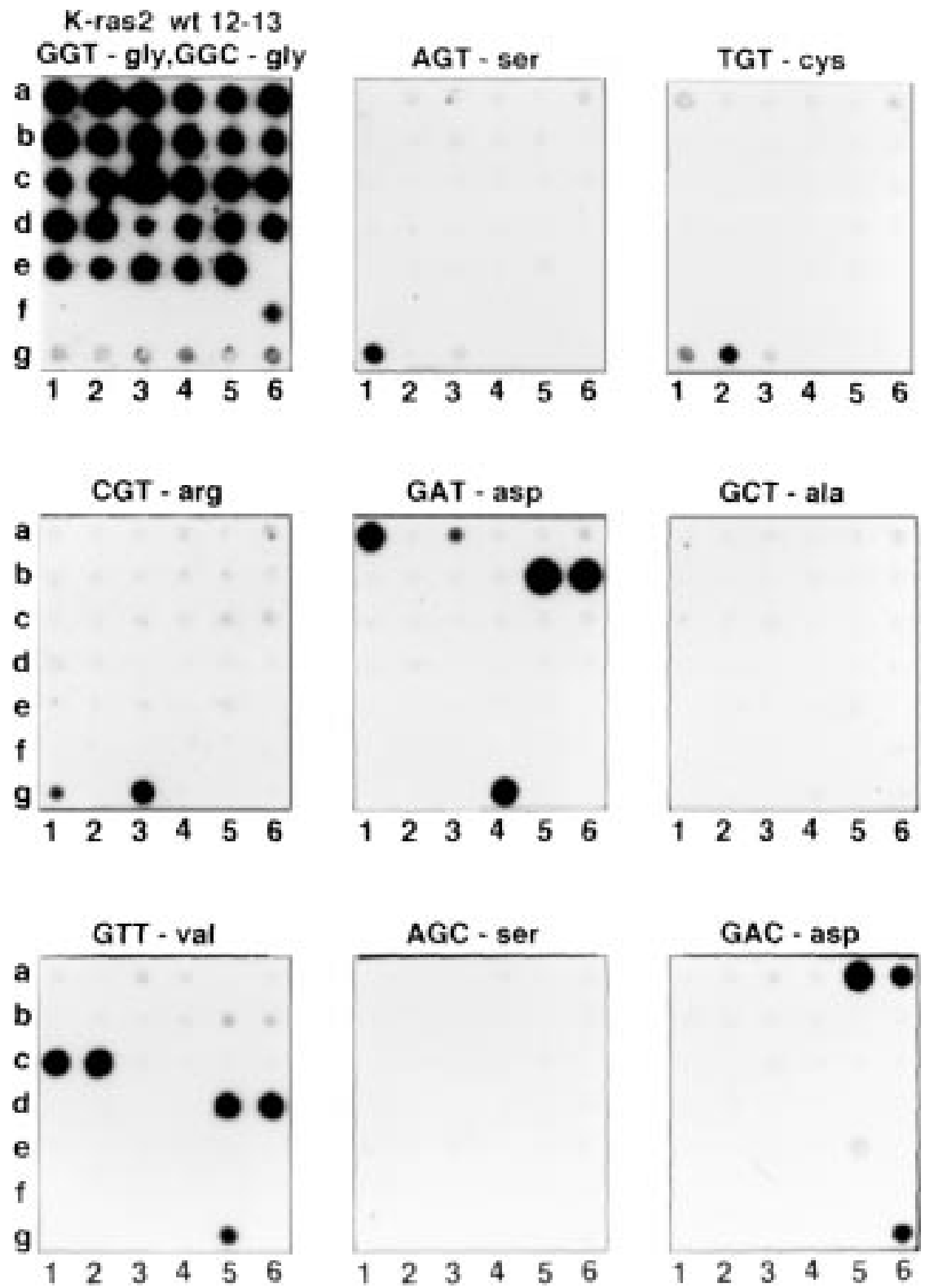

Fig. 1. Examples of k-ras mutation spectrum analysis for the adenomatous (A) and carcinomatous (C) components of human colorectal adenomas containing early cancer (A/C, as listed in Tables 1 and 3). Wild type k-ras results in codons 12 and 13, which correspond in both cases to the aminoacid glycin, are shown in the top-left rectangle (wt 12-13 GGT-gly, GGC-gly). Peripheral blood lymphocytes from a healthy donor were used as a k-ras wild type control (spot f6). The pairs of spots (a1-a2), (a3-a4), (a5-a6), (b1-b2), and so on up to (e3-e4) correspond to the wild type cases listed in Tables 1 and 3 under N. 24, 25, 26, 22, 23, 5, 14, 2, 8, 12, 13, 21, 16 and 1. An additional wild type case (the A component of case N. 6) corresponds to spot e5. The light grey spots g1-g6 correspond to 6 cell lines (respectively, A549, SW837, NIH3T3, SKLU-1, SW480 and DLD1) which had specific k-ras mutations in at least one allele. The cases with mutations are shown in the other rectangles: the 6 possible mutations in codon 12 (AGT-ser, TGT-cys, CGT-arg, GAT-asp, GCT-ala, GTT-val) and the 2 most common mutations in codon 13 (AGC-ser, GAC-asp). Specific k-ras mutation controls were obtained using mutated cell lines: the A549 cell line with heterozygous AGT mutation (g1); the SW837 cell line with heterozygous TGT mutation (g2); the NIH3T3 cell line with transfected CGT human mutated k-ras (g3); the SKLU-1 cell line with heterozygous GAT mutation (g4); the SW480 cell line with homozygous GTT mutation (g5); the DLD-1 cell line with heterozygous GAC mutation (g6) [15]. Identical k-ras mutations for the adenomatous and carcinomatous components of 4 human colorectal adenomas containing early cancer (these cases are listed in Tables 1 and 3 under the cases N. 4, 14, 21 and 26) corresponding to the pairs of spots GAT (b5-b6), GTT (c1-c2), GTT (d5-d6), and GAC (a5-a6) may be observed. 


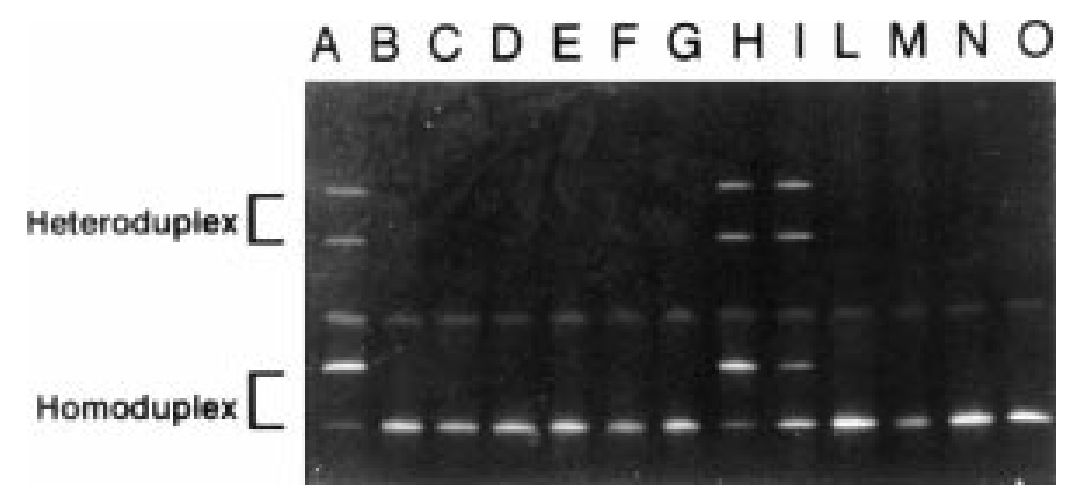

Fig. 2. PCR-based DGGE analysis examples of exon 8 of the p53 gene. A positive control obtained from the p53 mutated cell line SW480 mixed with normal lymphocyte is shown in lane A. A negative control obtained from normal lymphocytes DNA [7] is shown in lane O. DGGE variants corresponding to the adenomatous and carcinomatous components of the colorectal adenoma containing early cancer listed in Tables 1 and 3 under N. 22 are shown in lanes H and I.

Table 4

Heterogeneity for k-ras and p53 genetic status between adenomatous (A) and carcinomatous (C) component pairs for human colorectal adenomas containing early cancer $(\mathrm{A} / \mathrm{C})$

\begin{tabular}{|c|c|c|c|c|c|c|}
\hline & \multicolumn{2}{|c|}{ Homogeneous classes } & \multicolumn{3}{|c|}{ Heterogeneous classes } & \multirow[t]{2}{*}{ Heterogeneous cases } \\
\hline & $\mathrm{wt} / \mathrm{wt}$ & $\mathrm{m} / \mathrm{m}$ & $\mathrm{wt} / \mathrm{m}$ & $\mathrm{m} / \mathrm{wt}$ & $\mathrm{m} / \mathrm{m}^{\prime}$ & \\
\hline k-ras status in $\mathrm{A} / \mathrm{C}$ component pairs & 16 & 5 & 1 & 2 & 0 & $3 / 24(13 \%)$ \\
\hline p53 status in $\mathrm{A} / \mathrm{C}$ component pairs & 5 & 4 & 5 & 3 & 5 & $\begin{array}{c}13 / 22(59 \%) \\
p \text {-value }=0.002\end{array}$ \\
\hline
\end{tabular}

Table 5

Associations of k-ras and p53 mutational status with site, size, type and dysplasia among human colorectal adenomas containing early cancer

\begin{tabular}{|c|c|c|c|c|c|c|c|c|c|}
\hline & \multicolumn{2}{|c|}{ Site } & \multicolumn{3}{|c|}{ Size (mm) } & \multicolumn{2}{|c|}{ Type } & \multicolumn{2}{|c|}{ Dysplasia } \\
\hline & $\mathrm{R}$ & $\mathrm{L}$ & $\leqslant 10$ & $>10$ and $\leqslant 20$ & $>20$ & $\mathrm{~T}$ & $\mathrm{TV}+\mathrm{V}$ & MM & $\mathrm{S}$ \\
\hline \multicolumn{10}{|l|}{ k-ras } \\
\hline wild type & 9 & 9 & 4 & 7 & 6 & 7 & 11 & 7 & 11 \\
\hline mutated & 3 & 4 & 0 & 2 & 5 & 0 & 7 & 5 & 2 \\
\hline$p$-value & \multicolumn{2}{|c|}{$p=1$} & \multicolumn{3}{|c|}{$p=0.2$} & \multicolumn{2}{|c|}{$p=0.13$} & \multicolumn{2}{|c|}{$p=0.2$} \\
\hline \multicolumn{10}{|l|}{ p53 } \\
\hline wild type & 6 & 5 & 2 & 4 & 5 & 4 & 7 & 8 & 3 \\
\hline mutated & 5 & 7 & 2 & 4 & 6 & 3 & 9 & 2 & 10 \\
\hline$p$-value & \multicolumn{2}{|c|}{$p=0.7$} & \multicolumn{3}{|c|}{$p=0.97$} & \multicolumn{2}{|c|}{$p=0.67$} & \multicolumn{2}{|c|}{$p=0.012$} \\
\hline
\end{tabular}

Right colon (R) includes caecum, asceding colon, hepatic flexure and trasverse colon; Left colon (L) includes splenic flexure, descending colon, sigmoid colon and rectum. $\mathrm{T}=$ tubular type; $\mathrm{TV}=$ tubulovillous type; $\mathrm{V}=$ villous type. $\mathrm{MM}=$ mild and moderate dysplasia; $\mathrm{S}=$ severe dysplasia.

One may see that there are three types of heterogeneity: the cases within the $(\mathrm{wt} / \mathrm{m})$ class with wild type status for the adenomatous component and mutation for the carcinomatous component; the cases within the opposite ( $\mathrm{m} / \mathrm{wt})$ class; and the cases in which the adenomatous and carcinomatous components had different mutations ( $\mathrm{m} / \mathrm{m}^{\prime}$ class). In the case of k-ras, only 3 out of 24 cases were heterogeneous (13\%), while heterogene- ity was present for $\mathrm{p} 53$ in 13 out of 22 cases (59\%) $(p$-value $=0.002)$.

Among the adenomas containing early cancer, we have also analyzed the possible associations of k-ras and p53 mutational status within the adenomatous component with adenoma site, size, type, and dysplasia (Table 5). We found that $83 \%$ of the p53 mutated cases had severe dysplasia, providing a statistically signifi- 
Table 6

Analysis of k-ras and p53 mutations for 17 human colorectal adenomas having cancer in the near vicinity

\begin{tabular}{|c|c|c|c|c|c|}
\hline \multirow[t]{2}{*}{ N. } & \multirow[t]{2}{*}{ Category } & \multicolumn{2}{|r|}{ k-ras } & \multicolumn{2}{|c|}{ p53 } \\
\hline & & A & $\mathrm{C}$ & A & $\mathrm{C}$ \\
\hline 1 & $\mathrm{~A}+\mathrm{C}$ & GAT & GTT & - & Ex.7 \\
\hline 2 & $\mathrm{~A}+\mathrm{C}$ & wt & GTT & Ex.7 & Ex.5B \\
\hline 3 & $\mathrm{~A}+\mathrm{C}$ & TGT & - & wt & - \\
\hline 4 & $\mathrm{~A}+\mathrm{C}$ & TGT & wt & wt & wt \\
\hline 5 & $\mathrm{~A}+\mathrm{C}$ & TGT & $\mathrm{wt}^{*}$ & wt & $\mathrm{wt}^{*}$ \\
\hline 6 & $\mathrm{~A}+\mathrm{C}$ & $\mathrm{wt}$ & $\mathrm{wt}^{*}$ & $\mathrm{wt}$ & $\mathrm{wt}^{*}$ \\
\hline 7 & $\mathrm{~A}+\mathrm{C}$ & wt & $\mathrm{wt}^{*}$ & wt & $\mathrm{wt}^{*}$ \\
\hline 8 & $\mathrm{~A}+\mathrm{C}$ & TGT & $\mathrm{wt}^{*}$ & $\mathrm{wt}$ & $\mathrm{wt}^{*}$ \\
\hline 9 & $\mathrm{~A}+\mathrm{C}$ & wt & wt & wt & wt \\
\hline 10 & $\mathrm{~A}+\mathrm{C}$ & GAC & GTT & - & wt \\
\hline 11 & $\mathrm{~A}+\mathrm{C}$ & GAT & AGT & wt & wt \\
\hline 12 & $\mathrm{~A}+\mathrm{C}$ & wt & wt & wt & wt \\
\hline 13 & $\mathrm{~A}+\mathrm{C}$ & GAC & GAT/GAC & wt & Ex.6 \\
\hline 14 & $\mathrm{~A}+\mathrm{C}$ & $\mathrm{wt}$ & GAT/GAC** & - & Ex.6* \\
\hline 15 & $\mathrm{~A}+\mathrm{C}$ & wt & GAT/GAC* & wt & Ex.6* \\
\hline 16 & $\mathrm{~A}+\mathrm{C}$ & wt & wt & wt & Ex. 8 \\
\hline 17 & $\mathrm{~A}+\mathrm{C}$ & wt & $\mathrm{wt}^{*}$ & wt & Ex.8* \\
\hline
\end{tabular}

cantly association between p53 mutations and severe dysplasia $(p=0.01)$. We also observed an increase of $\mathrm{k}$-ras mutations among the adenomatous components having tubulo-villous and villous type but the association was not statistically significant $(p=0.1)$.

Table 6 shows the k-ras and p53 mutation analysis data obtained for 17 adenomas having cancer in the near vicinity and the corresponding cancers. Incidences of k-ras and p53 mutations for the adenomas were respectively $47 \%(8 / 17)$ and $7 \%(1 / 14)$, while for the carcinomas we obtained $55 \%(5 / 9)$ for k-ras and $44 \%$ (4/9) for $\mathrm{p} 53$.

\section{Discussion}

Human colorectal adenomas containing early cancer are relatively rare lesions that should provide the opportunity to observe some of the critical genetic events driving the transition from a preneoplastic to a neoplastic state. Pilot observations, done almost 12 years ago using this same human system, indicated that the adenoma-carcinoma transition was characterized by mutations of the p53 oncosuppressor gene [38]. A later model proposed that development of colorectal cancer was due to the cumulative effect of p53 with mutations of other genes like APC, k-ras, and DCC, rather than to an exact sequence of changes [9]. Recent understanding of these gene functions, however, stressed that in the original model of Vogelstein, contrary to the original proposal, the order of p53 mutations seems to be essential [3]

In the present study, we compared the frequencies of k-ras and p53 gene mutations in adenomas containing early cancer and determined their degree of intratumor heterogeneity among the adenomatous and carcinomatous components. This type of analysis should provide information on the relative timing and role of these mutations in association with a definitive growth advantage and selection of the progressing subclones. In fact, if a mutation is generated or selected late, when the adenoma was already formed, one should expect heterogeneity among the adenomatous and carcinomatous components.

Interestingly, mutations of the p53 gene were present in the carcinomatous components of the adenomas containing early cancer in approximately $50 \%$ of the cases that were not detected in the adenomatous components of the same adenomas. In addition, the p53 mutations within the adenomatous components were found to be statistically significantly associated with severe dysplasia. In contrast, the intratumor heterogeneity of the k-ras oncogene status between adenomatous and carcinomatous component pairs of the adenomas containing early cancer was relatively rare (in approximately $10 \%$ of the cases).

In the present study, we have also compared the incidence of mutations of the k-ras and p53 genes of adenomas containing early cancer with those of adenomas having cancer in the near vicinity. We found that the incidence of k-ras mutations was slightly higher in the adenomas having cancer in the near vicinity $(47 \%)$ than in the adenomatous or carcinomatous components of the adenomas containing early cancer $(28 \%$ in both cases), but that the difference in the present series of cases was not statistically significant. On the contrary, the incidences of p53 mutations of the adenomas containing early cancer (52 and 64\%, respectively, for the adenomatous and carcinomatous components) were statistically significantly higher than the incidence of p53 mutations for the adenomas having cancer in the near vicinity $(7 \%)$.

The present findings reinforce the previous conclusions on the role of k-ras and p53 mutations in colorectal tumor progression seen earlier in the literature [9, 38]. Additionally, the present study demonstrates the 
existence of genetic heterogeneity of p53 mutations and the high homogeneity of k-ras mutations during the adenoma-carcinoma sequence. We suggest that in a number of adenomas containing early cancer the type of mutations, in particular, of the p53 tumor suppressor gene, may also be relevant for tumor progression. In addition, the high intratumor heterogeneity of p53 mutations in a large number of cases suggests late occurrence of the p53 mutations. Thus, the present data suggest that the colorectal adenoma-carcinoma transition is dependent on the order of the k-ras and p53 mutations and that $\mathrm{p} 53$ mutations are later decisive players at this transition. In other words, it appears that the different biological roles of k-ras and p53 in human colorectal adenomas containing early cancer are reflected by their timing and therefore by their degree of heterogeneity. In this respect, k-ras mutations, which are mainly intratumor homogeneous between the adenomatous and carcinomatous components, appear as early events that do not have the potential to drive the adenoma-carcinoma transition. This also appears to be the case for human aberrant crypt foci, which are putative precursor lesions of the adenomas, for which k-ras mutations were recently detected in up to $80-90 \%$ of the cases $[31,32,37,40]$.

The functional roles of the ras and 53 genes in colorectal cancer development and progression have been the subject of excellent studies, that were also extensively reviewed in the literature, but they are still not fully understood $[3,9,19]$. In particular, new functions of the Ras and P53 proteins associated to proliferation, apoptosis, and chromosomal stability became recently evident with the discovery of a plethora of new effector pathways and different cellular mechanisms $[1,5,8,18$, 21,22,25,36,39].

Recently, we have also demonstrated that mutations of p53 and k-ras genes in human colorectal cancer were associated with DNA aneuploidy as assessed by flow cytometry [7,13-16] and that the results obtained for $\mathrm{k}$-ras in the adenomas were confirmed by other studies using in vitro models in which a mutated k-ras was transfected $[17,28,30]$.

In the present study we did not perform a correlative analysis of $\mathrm{k}$-ras and p53 mutations with flow cytometric DNA aneuploidy due to the fact that DNA aneuploidy in colorectal adenomas is often neardiploid [12,13] and that paraffin embedded material does not allow great sensitivities with this technique [33]. Other techniques, like FISH and CGH, may be more suitable toward these aims [26,34].

In conclusion, the present study indicates that while the k-ras genetic status was mainly homogeneous within the adenomatous and carcinomatous components of adenomas with early cancer, the p53 genetic status, in contrast, was highly heterogeneous. These findings confirm the relevant role of p53 mutations as a late event in colorectal carcinogenesis for the acquisition of malignancy and stress the specificity of the mutations. The role of k-ras remains less clear, though it appears more related to tumor initiation and maintenance than to tumor progression.

\section{References}

[1] H. Aktas, H. Cai and G.M. Cooper, Ras links growth factor signaling to cell cycle machinery via regulation of cyclin D1 and the CdK inhibitor p27 KIP1, Mol. Cell Biol. 17 (1997), 3850-3857.

[2] N. Arber, H. Hibshoosh, S.F. Moss, S.F. Sutterx, Y. Zhang, M. Begg, S. Wang, B. Weinstein and P.R. Holt, Increased expression of cyclin D1 is an early event in multistage colorectal carcinogenesis, Gastroenterology 110 (1996), 669-674.

[3] J.W. Arends, Molecular interactions in the Vogelstein model of colorectal carcinoma, J. Pathol. 190 (2000), 412-416.

[4] S.J. Baker, A.C. Preisinger, J.M. Jessup, C. Paraskeva, S. Markowitz, J.K. Willson, S. Hamilton and B.Vogelstein, p53 gene mutations occur in combination with $17 \mathrm{p}$ allelic deletions as late events in colorectal tumorogenesis, Cancer Res. 50 (1990), 7717-7722.

[5] G. Bollag and F. McCormick, Regulators and effectors of ras proteins, Ann. Rev. Cell Biol. 7 (1991), 601-632.

[6] J.L. Bos, E.L. Fearon, S.R. Hamilton, M. Verlaan de Vries, J.H. van Boom, A.J. Van der Eb and B. Vogelstein, Prevalence of ras gene mutations in human colorectal cancers, Nature $\mathbf{3 2 7}$ (1987), 293-297.

[7] P. Campomenosi, P. Assereto, M. Bogliolo, G. Fronza, A. Abbondandolo, A. Capasso, P.F. Bellomo, R. Monaco, A. Rapallo, A. Sciutto, R. Orecchia, E. Geido and W. Giaretti, p53 mutations and DNA ploidy in colorectal adenocarcinomas, Anal. Cell. Pathol. 17 (1998), 1-12.

[8] C.Y. Chen and D.V. Faller, Direction of p21ras-generated signals towards cell growth or apoptosis is determined by protein kinase C and Bcl-2, Oncogene 11 (1995), 1487-1498.

[9] E.R. Fearon and B. Vogelstein, A genetic model for colorectal tumorogenesis, Cell 61 (1990), 759-767.

[10] J.L. Fleiss, Statistical Methods for Rates and Proportions, 2nd edn, Wiley, New York, 1981.

[11] W. Giaretti, S. Sciallero, S. Bruno, E. Geido, H. Aste and A.Di Vinci, DNA flow cytometry of endoscopically examined colorectal adenomas and adenocarcinomas, Cytometry 9 (1988), 238-244.

[12] W. Giaretti and L. Santi, Tumour progression by DNA flow cytometry in human colorectal cancer, Int. J. Cancer 45 (1990), 597-603.

[13] W. Giaretti, A model of DNA aneuploidization and evolution in colorectal cancer, Lab. Invest. 71 (1994), 904-910. 
[14] W. Giaretti, N. Pujic, A. Rapallo, S. Nigro, A. Di Vinci, E. Geido and M. Risio, k-ras2 G-C and G-T transversions correlate with DNA aneuploidy in colorectal adenomas, Gastroenterology 108 (1995), 1040-1047.

[15] W. Giaretti, R. Monaco, N. Pujic, A. Rapallo, S. Nigro and E. Geido, Intratumor heterogeneity of k-ras2 mutations in colorectal adenocarcinomas. Association with degree of DNA aneuploidy, Am. J. Pathol. 149 (1996), 237-245.

[16] W. Giaretti, A. Rapallo, E. Geido, A. Sciutto, F. Merlo, M. Risio and F.P. Rossini, Specific k-ras2 mutations in human sporadic colorectal adenomas are associated to DNA near-diploid aneuploidy and inhibition of proliferation, Am. J. Pathol. 153 (1998), 1201-1209.

[17] N. Hagag, L. Diamond, R. Palermo and S. Lyubsky, High expression of ras p21 correlates with increased rate of abnormal mitosis in NIH3T3 cells, Oncogene 5 (1990), 1481-1489.

[18] A. Hall, Small GTP-binding proteins and the regulation of the actin cytoskeleton, Annu. Rev. Cell Biol. 10 (1994), 32-54.

[19] D. Hanahan and R.A. Weinberg, The hallmarks of cancer, Cell 100 (2000), 57-70.

[20] S. Ichii, S. Takeda, A. Horii, S. Nakatsuru, Y. Miyoshi, M. Emi, Y. Fujiwara, K. Koyama, J. Furuyama, J. Utsunomiya and Y. Nakamura, Detailed analysis of genetic alterations in colorectal tumors from patients with and without familial adenomatous polyposis (FAP), Oncogene 8 (1993), 2399-2405.

[21] R. Khosravi-Far, S. Campbell, K.L. Rossman and C.J. Der, Increasing complexity of Ras signal transduction: involvement of Rho family proteins, Adv. Cancer Res. 72 (1998), 57-107.

[22] L.J. Ko and C. Prives, p53: puzzle and paradigm, Genes Develop. 10 (1996), 1054-1072.

[23] F. Konishi and B.C. Morson, Pathology of colorectal adenomas: a colonoscopic survey, J. Clin. Pathol. 35 (1982), 830841.

[24] D.P. Lane, Cancer. p53, guardian of the genome, Nature 358 (1992), 15-16.

[25] A.J. Levine, p53, the cellular gatekeeper for growth and division, Cell 88 (1997), 323-331.

[26] G.A. Meijer, M.A. Hermsen, J.P. Baak, P.J. van Diest, S.G. Meuwissen, J.A. Beleien et al., Progression from colorectal adenoma to carcinoma is associated with non-random chromosomal gains as detected by comparative genomic hybridization, J. Clin. Pathol. 51(12) (1998), 901-909.

[27] M. Miyaki, M. Seki, M. Okamoto, A. Yamanaka, Y. Maeda, K. Tanaka, R. Kikuchi, T. Iwama, T. Ikeuchi, A. Tonomura, Y. Nakamura, R. White, Y. Miki, J. Utsunomiya and M. Koike, Genetic changes and histopathological types in colorectal tumors from patients with familial adenomatous polyposis, Cancer Res. 50 (1990), 7166-7173.
[28] S. Nigro, E. Geido, E. Infusini, R. Orecchia and W. Giaretti, Transfection of human mutated k-ras in mouse NIH-3T3 cells is associated with increased cloning efficiency and DNA aneuploidization, Int. J. Cancer 67 (1996), 871-875.

[29] C.D. Nobes and A. Hall, Rho, rac, and cdc42 GTPases regulate the assembly of multimolecular focal complexes associated with actin stress fibers, lamellipodia, and filopodia, Cell 81 (1995), 53-62.

[30] R. Orecchia, E. Infusini, A. Sciutto, A. Rapallo, A. Di Vinci, S. Nigro, E. Geido and W. Giaretti, Ki-ras activation in vitro affects G1 and G2M cell-cycle transit times and apoptosis, J. Pathol. 190 (2000), 423-429.

[31] K. Otori, K. Sugijama, T. Hasebe, S. Fukushima and H. Esumi, Emergence of adenomatous aberrant crypt foci (ACF) from hyperplastic ACF with concomitant increase in cell proliferation, Cancer Res. 55 (1995), 4743-4746.

[32] P.T. Pretlow, Aberrant crypt foci and k-ras mutations: early recognized players or innocent bystenders in colorectal carcinogenesis?, Gastroenterology 108 (1995), 600-603.

[33] P. Quirke, J.B.J. Fozard, M.F. Dixon, J.E.D. Dyson, G.R. Giles and C.C. Bird, DNA aneuploidy in colorectal adenomas, $\mathrm{Br}$. J. Cancer 53 (1986), 477-481.

[34] T. Ried, R. Knutzen, R. Steinbeck, H. Blegen, E. Schrock, K. Heselmeyer, S. du Manoir and G. Auer, Comparative genomic hybridization reveals a specific pattern of chromosomal gains and losses during the genesis of colorectal tumors, Genes Chromosome Cancer 15 (1996), 1-5.

[35] J. Sambrook, E.F. Fritsch and T. Maniatis, Molecular Cloning, Cold Spring Harbour Laboratory Press, New York, 1989.

[36] M. Serrano, E. Gomez-Lahoz, R.A. DePinho, D. Beach and D. Bar-Sagi, Inhibition of Ras-induced proliferation and cellular transformation by p16INK4, Science 267 (1995), 249-252.

[37] T. Takayama, S. Katsuki, Y. Takahashi, M. Ohi, S. Nojiri, S. Sakamaki, J. Kato, K. Kogawa, H. Miyake and Y. Niitsu, Aberrant crypt foci of the colon as precursors of adenoma and cancer, New Engl. J. Med. 339 (1998), 1277-1284.

[38] B. Vogelstein, E.R. Fearon, S.R. Hamilton, S. Kern, A.C. Preisinger, B.A.M. Leppert, Y. Nakamura, R. White, A.M.M. Smits and J.L. Bos, Genetic alterations during colorectal-tumour development, New Engl. J. Med. 319 (1988), 525-532.

[39] R.L. Ward, A.V. Todd, F. Santiago, T. O'Connor and N. Hawkins, Activation of the k-ras oncogene in colorectal neoplasms is associated with decreased apoptosis, Cancer $\mathbf{7 9}$ (1997), 1106-1113.

[40] N. Yamashita, T. Minamoto, A. Ochiai, M. Onda and H. Esumi, Frequent and characteristic k-ras activation and absence of p53 protein accumulation in aberrant cript foci of the colon, Gastroenterology 108 (1995), 434-440. 


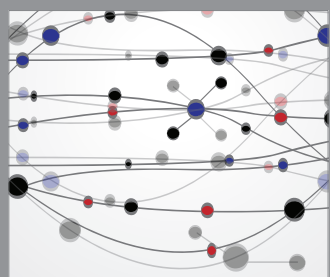

The Scientific World Journal
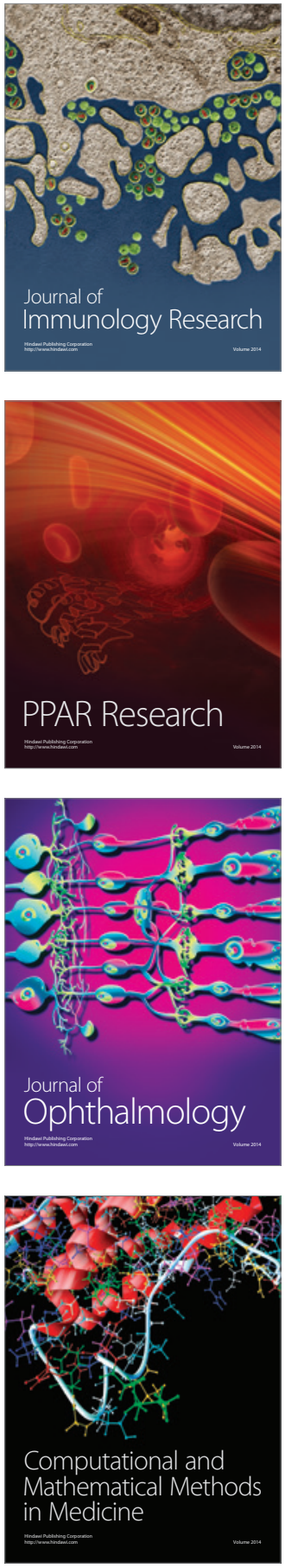

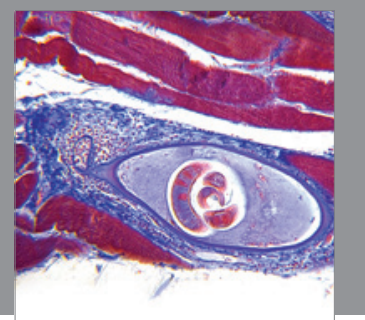

Gastroenterology

Research and Practice
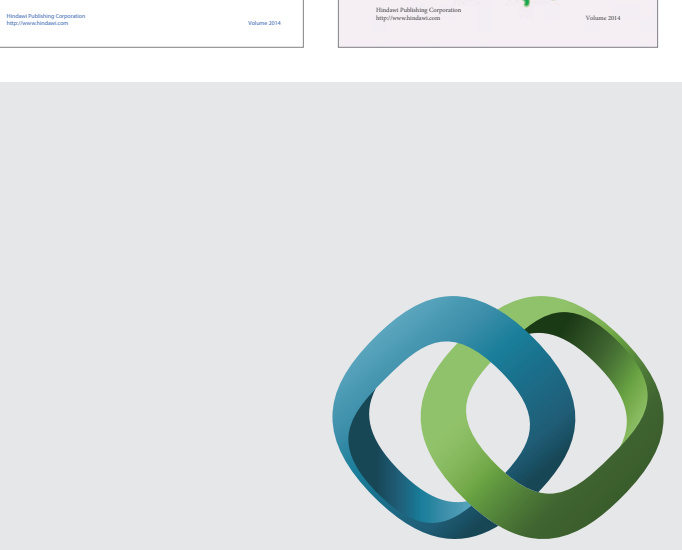

\section{Hindawi}

Submit your manuscripts at

http://www.hindawi.com
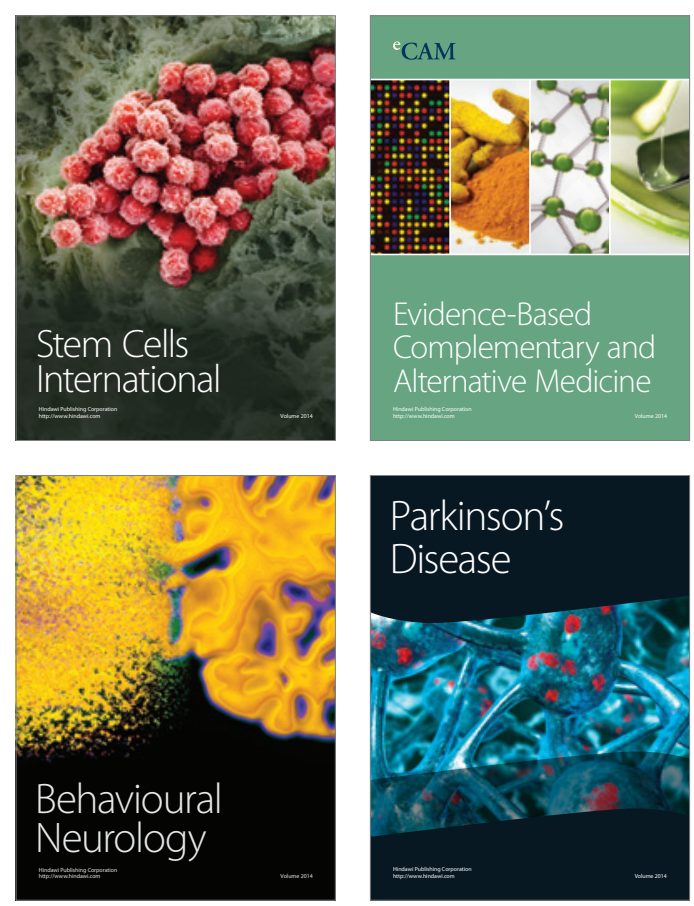

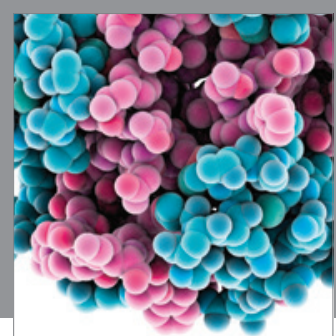

Journal of
Diabetes Research

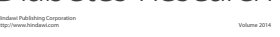

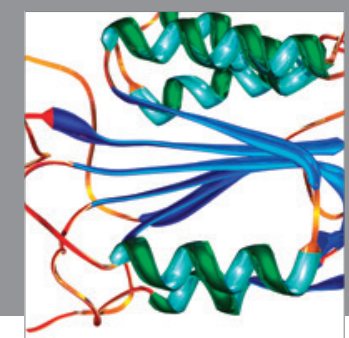

Disease Markers
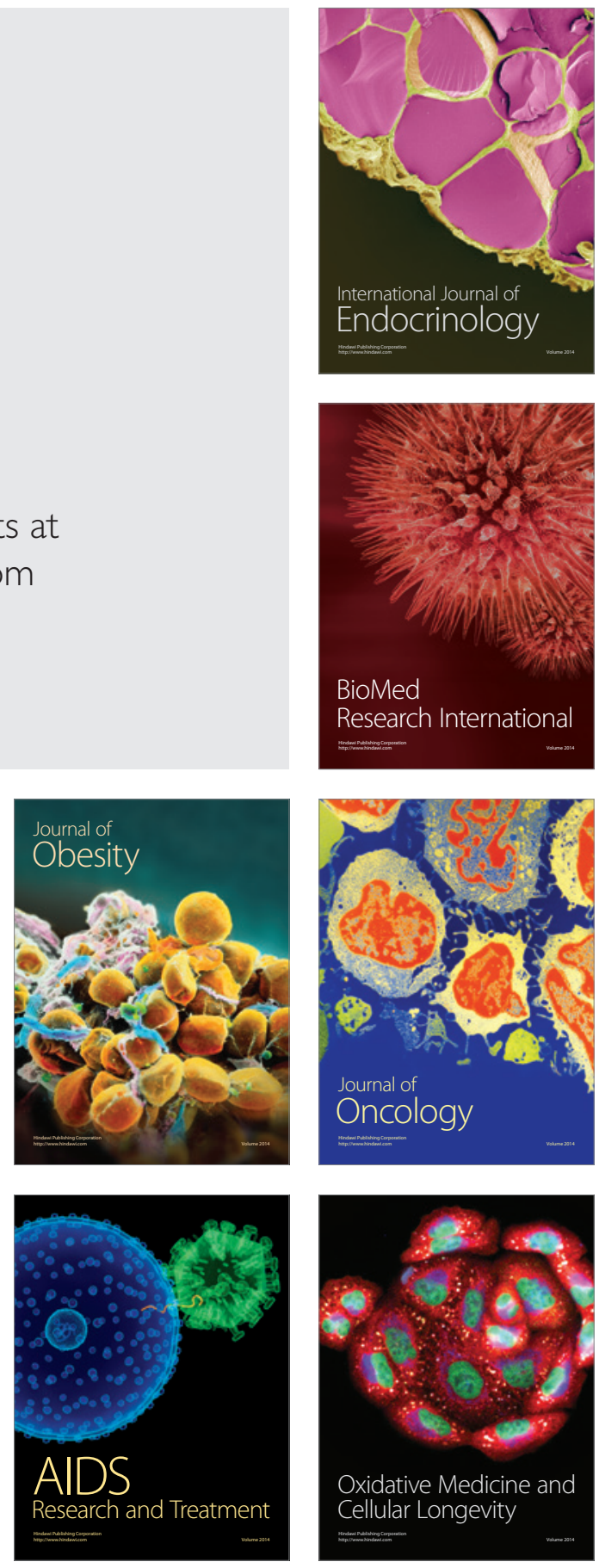